Published in final edited form as:

Inflamm Bowel Dis. 2015 August ; 21(8): E18-E19. doi:10.1097/MIB.0000000000000485.

\title{
Reply to Letter
}

\author{
Hamed Khalili, MD, MPH ${ }^{\star}$ and Andrew T. Chan, MD, MPH ${ }^{\star}{ }^{\dagger}$ \\ *Division of Gastroenterology Massachusetts General Hospital and Harvard Medical School \\ Boston, Massachusetts \\ †Channing Laboratory Department of Medicine Brigham and Women's Hospital and Harvard \\ Medical School Boston, Massachusetts
}

To the editors,

We appreciate the comments by Mendell et. al. regarding our study "Measures of Obesity and Risk of Crohn's Disease and Ulcerative Colitis". We are also pleased to review the results of the study by Harsoe, et. al. confirming our findings that obesity, as measured by body mass index (BMI), is associated with an increased risk of Crohn's disease (CD) ${ }^{1}$. We did not initially reference this study since it was published after our paper was initially submitted to Inflammatory Bowel Diseases ${ }^{1,2}$. As stated in our methods section, we did examine the possibility of a non-linear association between obesity and risk of CD and UC using a previously reported non-parametric cubic spline method ${ }^{3}$. This method allowed us to examine non-linear associations including $\mathrm{J}$ - and $\mathrm{U}$-shaped relationships between obesity of risk of $\mathrm{CD}$. However, we did not find such associations between baseline BMI, updated BMI, BMI at age 18, and risk of CD. Nevertheless, as we collected environmental data every 2 years, it's possible that the previously recognized U-shaped relationship is only observed with BMI information collected closer to the time of diagnosis. With regards to a dose relationship, among participants with BMI $\geq 30$ at baseline, age 18, or at least 2 years prior to diagnosis, we only had one case of $\mathrm{CD}$ with $\mathrm{BMI}>35$; thus, we were not able to specifically assess for presence of a dose-relationship among obese participants.

Sincerely,

Hamed Khalili ${ }^{1}$ MD MPH, Andrew T. Chan ${ }^{1,2}$ MD MPH

1) Division of Gastroenterology, Massachusetts General Hospital and Harvard Medical School, Boston MA 02114

2) Channing Laboratory, Department of Medicine, Brigham and Women's Hospital and Harvard Medical School, Boston, MA

Correspondence: Hamed Khalili, MD, MPH, Gastrointestinal Unit, Massachusetts General Hospital, 165 Cambridge St. $9^{\text {th }}$ floor, Boston, MA 02114. Phone: 617-724-6005 Fax: 617-726-3080; hkhalili@mgh.harvard.edu

Massachusetts General Hospital Gastroenterology Associates 55 Fruit St., Blake 4 Boston, Massachusetts 02114 UNITED STATES hkhalili@partners.org. 


\section{References}

1. Harpsoe MC, Basit S, Andersson M, et al. Body mass index and risk of autoimmune diseases: a study within the Danish National Birth Cohort. Int J Epidemiol. 2014; 43:843-55. [PubMed: 24609069]

2. Khalili H, Ananthakrishnan AN, Konijeti GG, et al. Measures of obesity and risk of Crohn's disease and ulcerative colitis. Inflamm Bowel Dis. 2015; 21:361-8. [PubMed: 25563694]

3. Durrleman S, Simon R. Flexible regression models with cubic splines. Stat Med. 1989; 8:551-61. [PubMed: 2657958] 